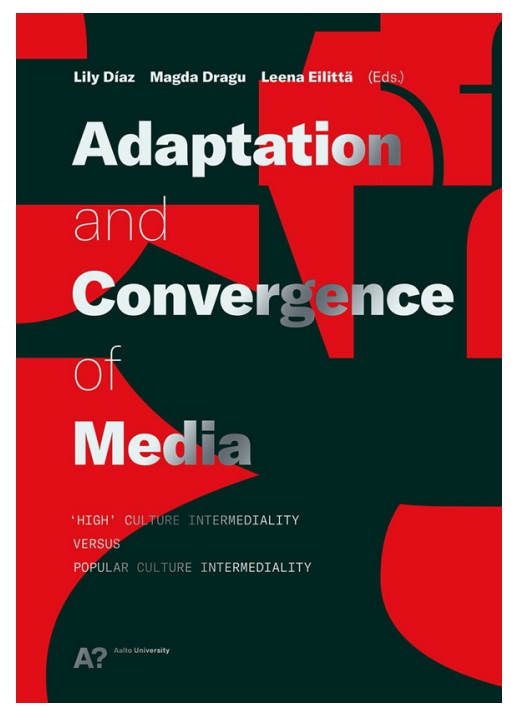

\section{ADAPTAATIOT "KORKEAN" JA "MATALAN" KULTTUURIN SILLANRAKENTAJINA}

Lily Díaz, Magda Dragu \& Leena Eilittä (eds.) (2018) Adaptation and Convergence of Media. 'High' Culture Intermediality versus Popular Culture Intermediality. Aalto ARTS Books: Espoo, 276 s.
Lily Díazin, Magda Dragun ja Leena Eilittän toimittama Adaptation and Convergence of Media. 'High' Culture Intermediality versus Popular Culture Intermediality on kokoelma, jonka tavoitteena on huomioida niin temaattisia kuin muodollisiakin yhteyksiä intermediaalisuuden ja populaarikulttuurin välillä. Johdantoon ja kolmeen käsittelyosaan jaettu artikkelikokoelma lähestyy teemaa perinteisen populaarikulttuuri-korkeakulttuuri-jaottelun kautta, ja toimittajat määrittelevätkin johdannossa huolella miten nämä kaksi eroavat toisistaan. Suurin osa artikkeleista käsittelee kirjoittajien määrittelemää "suuren yleisön" suosimaa kulttuuria, kuten elokuvia, sarjakuvia, televisiota ja pelejä. Tämän vastapainona toisissa teksteissä käsitellään klassista musiikkia ja maalaustaidetta, korkeakirjallisuutta ja kuvataidetta, jotka toimittajat määrittelevät yhtäältä niiden virallisen aseman, ja toisaalta pienempien yleisöjen kautta. Jää hieman kyseenalaiseksi, edustavatko näiden tekstien analyysin kohteena olevat teokset niin sanottua virallista kulttuuria, samoin kuin epäilen niiden yleisöjen pienuutta. Koen monilla tavoin ongelmalliseksi ja turhauttavaksi jaottelun populaarikulttuurin ja korkeakulttuurin osaalueisiin, kun kirjan 13 artikkelia olisi voinut jakaa myös monella muulla tavalla suhteessa adaptaatioon ja intermediaalisuuteen.

Kirjan aloittavassa johdannossa Ken Friedman ja Lily Díaz avaavat intermedian käsitettä. Kirjoittajien tavoitteena on muistuttaa intermedia-käsitteen merkittävistä hyödyistä ja historiallisen analyysin avulla osoittaa kä- sitteen hyödyllisyys tämän päivän teoreettisia pohdintoja varten. Díaz ja Friedman toteavat intermedian käsitteellisen merkityksen kumpuavan sen suhteesta uuteen mediaan: se levittäytyy käsitteenä mediarajojen yli ja tarjoaa sysäyksen uusmedialle. Kirjoittajat tekevät myös käsitteellistä eroa multimedian ja intermedian välillä ja muistuttavat, että vaikka multimedialla tarkoitetaan usein esitystä tai taidetta, jossa käytetään apuna monia eri teknologioita, jo elokuva, ooppera ja tv-lähetys ovat multimediaesityksiä, sillä niissä tuotetaan sisältöä usealle aistille samalla kertaa. Magda Dragu jatkaa johdannon pohdintaa omassa artikkelissaan, jossa hän käsittelee intermediaalisen viittauksen (intermedial reference) käsitteen avulla visuaalisia fuugia, eli musiikkia visualisoivia maalauksia.

Artikkeleiden joukosta löytyy varsin perinteisiä adaptaatiotutkimuksia, joissa vertaillaan käännöstutkimuksesta tutuin termein lähde-ja kohdetekstejä toisiinsa. Ensimmäinen niistä on Bianca Thiem-Mahdavin F. Scott Fitzgeraldin Kultahattu-romaanin (1925) sekä Baz Luhrmanin The Great Gatsby -elokuvan (2013) välisiä eroja ja yhtäläisyyksiä käsittelevä teksti. Thiem-Mahdavi toteaa analyysissaan, että adaptaatiot ovat kulttuurisia kertomuksia, jotka keskittyvät uudelleen kertomiseen ja näyttämiseen. Lähes satavuotiaan romaanin teemat säilyvät ajankohtaisina elokuvassa, koska alkuperäisteoksen kerronta muuttuu konvergenssin myötä. Adaptaatio, jonka kirjoittaja käsittää kulttuurisena kertomuksena, säilyttää sopivan määrän teoksen teemoista, 
jotta se on tunnistettava, mutta elokuvan mukanaan tuomat mahdollisuudet uudistavat sitä sopivasti.

Melko perinteisestä adaptaatiotutkimuksen näkökulmasta aihettaan lähestyy myös Alejandro Pedregal, joka käsittelee Adam McKayn The Big Short -elokuvaa (2015). Pedregal kysyy esimerkiksi, mitä keinoja elokuvassa käytetään adaptoimaan sen lähdetekstinä olevaa tietokirjaa, ja miten nämä keinot ovat johtaneet siihen, että elokuva on erilainen kuin sen pohjana oleva kirja. Toisaalta artikkelissa tutkitaan pikemminkin yhteiskunnallisen ilmiön kuin tietokirjan elokuva-adaptaatiota. Tuomalla The Big Shortin lisäksi rinnalle kahden muun elokuvan analyysit, Pedregal pohtii, miten vuoden 2008 finanssikriisi on adaptoitu elokuvaksi.

Thiem-Madhavin ja Pedregalin artikkelit ilmentävät kokoelman keinotekoiselta tuntuvaa jakoa populaari- ja korkeakulttuurin välillä. Ensin mainittu löytyy kirjan avaavasta, taidetta käsittelevästä osiosta, kun taas jälkimmäinen populaarikulttuurin ja intermediaalisuuden analyyseille omistetusta osasta. Elokuvat ovat eroistaan huolimatta varsin samalla viivalla suosion, yleisöjen ja niin sanotun laadun suhteen; sekä Luhrmanin että McKayn elokuvat ovat Hollywood-tuotantoja, palkintogaalojen ehdokkaita ja kassamenestyksiä. Erottavana tekijänä vaikuttaa olevan lähdeteksti, jossa toisessa on kaunokirjallinen teos ja toisessa tietokirja.

Tämä osoittaa korkean ja matalan kulttuurin välisen vastakkainasettelun ongelman suhteessa adaptaatioon. Adaptaatio nimenomaan tarjoaa mahdollisuuden uusiin tulkintoihin, ja kuten Jouko Aaltonen toteaa Ian W. Macdonaldia siteeraten omassa artikkelissaan (s. 173), adaptaatio voidaan nähdä myös prosessina, jossa sama idea matkustaa usean eri median läpi (sit. Macdonald 2013, 2). Onko mielekästä jakaa analyyseja korkean ja matalan kulttuurin, tai suurten ja pienten yleisöjen mukaan, kun adaptaatio mahdollistaa muutoksen niin sanotusta matalasta tai populaarista korkeaan, sekä päinvastoin?

Ei-fiktiivisen teoksen adaptaatiota fiktion keinoin pohtii artikkelissaan myös Jouko Aaltonen, joka käsittelee tekstissään fiktion ja dokumentin konvergenssia. Hän esittää dokumentin ja fiktion olevan kietoutuneita toisiinsa epistemologisesti, sosiaalisesti sekä tyylin ja ilmaisun näkökulmasta. Aaltonen pyrkii valaisemaan tätä analysoimalla, miten dokumentit ovat vaikuttaneet fiktioon. Toisin kuin The Big Short, joka on pikemminkin viihteellinen dokumentti kuin fiktiivinen elokuva, Aaltosen analyysikohteena on fiktioelokuvia, joiden pohjana tai juonen tärkeänä osana on dokumenttielokuva tai -tv-sarja.

Katriina Heljakan ja Pirita Ihamäen artikkelissa tutkitaan taiteen ja pelin konvergenssiä geokätköilyn maailmassa. Artikkelin tutkimuskohteena on käyttäjien kokemukset taide-geokätköily-polusta, johon oli yhdistetty visuaalista taidetta, nukkehahmo ja geokätköilyyn liittyviä vihjeitä. Tutkimuksen mukaan taiteellisten töiden leikillisyys lisäsi ja rikastutti käyttäjien ymmärrystä itse taiteesta, ja tämä oli taiteen ja pelin konvergenssin ansiota. Myös osallistavuus oli tärkeä elementti pelissä. Heljakan ja Ihamäen artikkelissa päästään hieman populaarikulttuurin ja korkean kulttuurin välisen aidan rikkomiseen. Kirjoittajat toteavat, että käyttäjien aktivoimisesta on tullut erityisesti museoille tärkeää viime vuosina. Nykykulttuurimme vaatii ja janoaa pelillisiä kokemuksia, eikä taidemaailma jää tässä hännille. Populaarikulttuurin piiriin kuuluva geokätköily, johon on lisätty entistä enemmän pelillistäviä elementtejä nukkehahmoineen, yhdistetään kirjoittajien projektissa kuvataiteeseen, jota artikkelikokoelman kontekstissa pidetään korkeana kulttuurina, ja näin ollen pienempien yleisöjen kiinnostuksen kohteena. Tästäkin voidaan toisaalta olla montaa mieltä, sillä hankkeet kuten Museokortti ovat varmasti vaikuttaneet siihen, etteivät museotkaan ole enää "pienempien yleisöjen" korkeakulttuuria.

Kokoelman toimittajien määrittelemää eroa käsitteellistetään toisessakin artikkelissa. Hanna E. Psychas analysoi artikkelissaan kudontaa matalan ja korkean kulttuurin välisenä prosessina ja pohtii käsitöiden suhdetta taiteeseen. Erityisesti tekstiilitöiden ja kudelmien suhde taiteeseen on ollut kiistanalainen, mistä syystä ne on yhdistetty amatöörimäisyyteen ja ajateltu kuuluvat kodin piiriin. Artikkelin yhteys adaptaatioon tai konvergenssiin jää hieman hämäräksi, ja kiinnostavasta lähtökohdastaan huolimatta siinä ei tunnuta vastaavan mihinkään tutkimuskysymykseen. Artikkeli kuitenkin puolustaa paikkaansa kokoelmassa pohtimalla matalan ja korkean kulttuurin välisiä rajoja ja 
merkityksiä; miksi käsityöt nähdään matalana kulttuurina, miten Kalevala muuttui taiteeksi ja lopulta Suomen historiaksi tullessaan kirjoitetuksi tekstimuotoon runonlaulantaperinteen sijaan. Taiteen julistaminen historiaksi on Psychasin mukaan eräänlaista matalan ja korkean kulttuurin välistä kudontaa.

Vaikka Díazin, Dragun ja Eilittän ratkaisu nimetä ja jaotella kokoelma perinteistä korkea-populaari-vastakkainasettelua mukaillen tuntuu turhauttavalta ja tarpeettomalta, itse artikkeleissa pohditaan kiinnostavalla tavalla sekä perinteisempiä adaptaatiotutkimuksen kohteita (elokuva vs. kirja), että tehdään yllättävämpiä tulkintoja konvergenssista ja adaptaatiosta. David Havas esimerkiksi käsittelee tšekkoslovakialaisessa nuortenlehdessä ilmestynyttä sarjakuvastrippiä, jossa rohkaistiin nuoria lukijoita perustamaan kerhoja ja toteuttamaan sarjakuvassa nähtyä toimintaa todellisessa elämässä. Sarjakuvan kirjoittaja kehotti lukijoita järjestäytymään, vaikka se oli kiellettyä kommunistisen vallan alla. Kerhot olivat utopiaa, eivät fantasiamaailmaa; ne olivat vain hieman erilaista kuin todellinen elämä. Populaarikulttuurin tuotteet on tarkoitettu adaptoitavaksi, ja niiden helppo saatavuus tekee populaarikulttuurista toisinaan kumouksellisempaa kuin taiteesta, kuten Havas osoittaa analyysissaan.
Havasin artikkelin lisäksi toinenkin teksti yllättää tuomalla adaptaation ja konvergenssin käsitteet eri medioiden vertailusta todelliseen maailmaan. Mediaekologiaa tutkiva Anna Boswell kirjoittaa konvergenssista ekologisena käsitteenä yhdistelemällä biodiversiteetin ja lajien elämään liittyviä diskursseja uusien media-alustojen sekä osallistumisen muotoihin. Boswell kysyy, miksi mediatutkijat eivät ole ekokatastrofin uhatessa tarttuneet Henry Jenkinsiltä tuttuihin osallistuvan kulttuurin (participatory culture) ja kollektiivisen älyn käsitteisiin tarkemmin kriisin ratkaisuja etsittäessä. Boswell muistuttaa adaptaation tarkoittavan myös lajien sopeutumista, ja konvergenssin vastakohtana voidaan nähdä vaihtoehtojen kaventuminen ja elintilan pienentyminen. Tämä tärkeä pohdinta nousi yllättäen esiin ja tuntui tervetulleelta media-adaptaatioita käsittelevässä kokoelmassa.

\section{Laura Antola}

FM, mediatutkimus, Turun yliopisto

\section{Lähteet}

Macdonald, Ian W. (2013) Screenwriting Poetics and the Screen Idea. New York: Palgrave Macmillan. 